\title{
A conjugação dos verbos irregulares na 1. a pessoa do singular do pretérito perfeito simples do indicativo nos dialetos do português europeu e tipologia das alterações ocorrentes
}

\section{Conjugation of Irregular Verbs in the $1^{\text {st }}$ Person Singular of the Past Simple \\ Tense in the Dialects of European Portuguese and the Typology \\ of its Alternations}

Petra Svobodová [petra.svobodova@upol.cz]

Univerzita Palackého v Olomouci, República Checa

\section{RESUMO}

$\mathrm{O}$ artigo debruça-se sobre alterações da flexão verbal ocorrentes nos dialetos continentais do português europeu. Concretamente, aborda as principais alteraçoes da $1 .^{a}$ pessoa do singular do pretérito perfeito simples do indicativo dos verbos irregulares, descrevendo-as linguisticamente, incluindo o seu surgimento, evolução e distribuição geográfica. Baseando-se nesta descrição, tenta classificar as alterações da flexão dos verbos irregulares em três tipos básicos: alterações fonéticas, quando a mudança de forma da desinência verbal reflete apenas fenómenos fonéticos gerais que ocorrem em todos os contextos linguísticos do mesmo tipo, não se modificando, assim, o paradigma verbal; depois alterações morfológicas, que são aplicadas propositadamente ou para diferenciar duas formas verbais semelhantes ou ainda para assimilar uma forma verbal a outra já existente, considerada prototípica; e, finalmente, alterações morfonológicas, quando se aplica uma alteração fonética na desinência ou no radical que depois, por consequência, começa a desempenhar papel distintivo a nível do paradigma flexional.

\section{Palavras-Chave}

dialetologia; flexão verbal; verbos irregulares; primeira pessoa singular; pretérito perfeito simples do indicativo

\section{Abstract}

The paper is dedicated to the alternations of verbal flection in the dialects of European Portuguese. It concentrates on the alternations in the $1^{\text {st }}$ person singular in the past simple tense of irregular verbs and describes them from the linguistic perspective, including information about their origin, evolution and diatopic distribution. Subsequently, the text intends to classify these alternations into three groups. The first one is represented by mere phonetic alternations when the alternations of verbal flection reflect some general phonetic phenomena which appear in all similar linguistic contexts regardless of the word class, having thus no impact on the verb paradigm. The second one includes morphological alternations which are applied deliberately either to differentiate two similar or identical verb forms, or to assimilate a verb 
form to another form considered prototypical. The third group comprises morphophonetic alternations when an accidental phonetic alternation employed in verbal flection subsequently acquires a distinctive role in verb paradigm.

\section{KEYWORDS}

dialectology; verbal flection; irregular verbs; first person singular; past simple tense

RECEBIDO 2017-08-22; ACEITE 2017-10-23

\section{Introdução}

O verbo representa uma das classes de palavras mais dinâmicas e ricas em variação. A sua conjugação dispõe de enorme número de variantes, não só na língua padrão como também nas suas variedades diatópicas. Apesar de os dialetos portugueses serem tradicionalmente considerados bastante homogéneos ${ }^{1}$ e as alterações a nível morfológico escassas ${ }^{2}$ e pouco sistemáticas $^{3}$, o verbo, pelo menos em alguns dos seus tempos, representa uma exceção. A flexão verbal nos dialetos do português europeu dispõe de bastantes peculiaridades, e estas oferecem, sem dúvida, um vasto campo de estudo.

A variação atinge todos os tipos de verbos e todos os tempos verbais. No que diz respeito aos tipos de verbos, deparamo-nos com variação de desinência e até de forma do radical tanto nos verbos regulares como nos verbos irregulares, embora a variação destes últimos seja, obviamente, mais diversa e os motivos que levam a essa maior diversidade sejam também mais variados e, de vez em quando, até contraditórios, tendo em conta que existe uma tendência tanto para assemelhar formas verbais diferentes, regularizando assim o paradigma verbal, como para diferenciar formas verbais assaz semelhantes. No que toca aos tempos mais frequentemente sujeitos à variação, são predominantemente os que aparecem com maior frequência na fala dia a dia e que, por serem morfologicamente mais complexos, suscitam incerteza acerca da sua flexão. Portanto, em princípio, é com o presente do indicativo e também com o pretérito perfeito simples do indicativo que nos deparamos mais nos inquéritos dialetais. Os restantes tempos são, na fala, de uso muito reduzido ou até omissos por completo (como, por exemplo, o futuro do pretérito composto do indicativo), ou substituídos por perífrases verbais com significado mais ou menos correspondente, tal como acontece, por exemplo, no caso do futuro do presente simples do indicativo, que costuma ser expresso através da locução verbal do verbo auxiliar ir

1 Manuel de Paiva Boléo fala de «homogeneidade excepcional» que «não tem paralelo em qualquer outra língua da Europa» (Boléo 1974: 260).

2 A variação diatópica é considerada muito mais marcante a nível fonético e lexical do que sintático e morfológico, tal como confirmam Peres e Móia ao dizer que «variação dentro do espaço português é [...] forte nos planos lexical e fonético, onde a diversidade é acentuada» (Peres - Móia 1997: 37).

3 Pressupõe-se que um fenómeno da variação morfológica ou é distribuído por todo o território português, e assim não é geograficamente marcado, ou aparece esporadicamente em zonas isoladas e distantes uma da outra, o que não ajuda na delimitação de uma sub-região dialetal, já que não pode ser considerado traço típico e representativo daquela zona. (veja-se, por ex., Cuesta 1989: 66). 
com o infinitivo do verbo significativo. Finalmente, há também casos em que um tempo verbal é substituído por outros tempos verbais que, na língua padrão, podem servir para indicar circunstâncias temporais bastante diferentes. Isto sucede, por exemplo, no caso do presente do indicativo e do presente do conjuntivo, que se confundem frequentemente ${ }^{4}$, bem como no caso do pretérito perfeito simples do indicativo, habitualmente expresso pelo pretérito mais-queperfeito simples do indicativo ${ }^{5}$ ou pelo pretérito perfeito composto do indicativo ${ }^{6}$.

Devido aos fatores acima referidos, vamos dedicar-nos à variação flexional no tempo no qual os verbos irregulares, a nosso ver, dispõem de maior variabilidade, ou seja, no pretérito perfeito simples do indicativo; quanto à pessoa verbal, concentrar-nos-emos na $1 .^{\mathrm{a}}$ pessoa do singular, porque nela damos conta de variedades tais que sentimos ilustrarem com clareza o que desejamos atingir como objetivo principal: mostrar que as alterações ocorrentes nos verbos podem subdividir-se, segundo a motivação da sua aplicação, em três tipos básicos. Escolhendo apenas alguns dos muitos fenómenos inerentes a esta pessoa verbal e descrevendo-os, explicando simultaneamente os contextos peculiares pelos quais podem ser, e geralmente são, condicionados, vamos assim poder demonstrar que, na alteração diatópica dos verbos, identificamos mudanças classificáveis como alterações de caráter fonético, alterações morfológicas e alterações morfonológicas.

Para exemplificar os fenómenos referidos, vamos socorrer-nos de um corpus dialetológico que criámos com base em duas fontes principais. Primeiro, baseámo-nos em 71 teses de doutoramento realizadas nos anos 50 e 60 do século $\mathrm{XX}^{7}$. Segundo, aproveitámos de 176 inquéritos dialetais criados por Lindley Cintra e realizados entre os anos 70 do século XX e o início do século XXI, ${ }^{8}$ recolhendo os dados das transcrições realizadas nos próprios inquéritos pela equipa da Dialetologia e Diacronia do Centro de Linguística da Universidade de Lisboa. Mesmo que estes inquéritos não abranjam muitos fenómenos de caráter morfológico, sempre nos fornecem uma quantidade suficiente de dados para análise. Assim, juntando dados tanto das teses consultadas quanto dos inquéritos de Cintra, conseguimos no total criar um corpus que oferece informações de 247 localidades espalhadas por todo Portugal continental, o que consideramos uma base suficiente para uma análise fiável.

4 Esta troca costuma ser frequentemente restrita a uma só pessoa verbal, tipicamente a 1. ${ }^{\text {a }}$ pessoa do plural, quando deparamos com formas verbais como, por exemplo, FALAMOS realizadas como FALEMOS. Porém, esta alteração pode ser, eventualmente, explicada não como troca dos dois tempos, mas como uma alteração de caráter meramente fonético, sendo - em algumas regiões, como a Beira Baixa - a troca da vogal A por E realizada não apenas nas desinências verbais mas também noutras classes de palavras (Svobodová 2011: 115).

5 Fenómeno que ocorre, antes do mais, no caso de verbos regulares, tal como mostra o exemplo da zona de Viana do Castelo, em que a 1. ${ }^{\text {a }}$ pes. do sing. ANDEI se realiza como ANDARA (Svobodová 2011: 117).

6 Este fenómeno pode aparecer tanto nos verbos regulares como nos verbos irregulares e, como encontramos exemplos dele especialmente nas zonas fronteiriças com Espanha, deve-se, provavelmente, a uma certa interferência do espanhol falado. Assim, por exemplo na região do Alto Alentejo deparamos com formas verbais como TENHO FEITO em vez de FIZ (Svobodová 2011: 116).

7 As teses foram realizadas nas Universidades de Lisboa e de Coimbra com o objetivo de descrever pormenorizadamente falares de localidades concretas, concentrando-se, em particular, no léxico mas abrangendo marginalmente também o nível morfológico dos respetivos falares. Os exeplos dos fenómenos referidos neste texto são citados da tese de doutoramento da autora, que se baseou neste corpus e na qual se pode consultar a lista completa das teses (Svobodová 2011: 180-183).

8 Primeiro pelo próprio Cintra e depois da sua morte em 1991 pelo grupo de investigação na área de dialetologia. 


\section{Alterações fonéticas}

Por alterações fonéticas entendemos as que refletem fenómenos fonéticos gerais suscetíveis de ocorrer em todas as classes de palavras num mesmo contexto linguístico. Elas nunca influenciam o paradigma flexional do verbo em questão de maneira significativa, pelo que representam apenas variedades de pronúncia. Devido ao seu caráter geral, são muito mais frequentes nas desinências dos verbos regulares, mas podemos encontrar algumas alterações deste tipo também nos verbos irregulares. Como um dos poucos exemplos de alterações fonéticas pode ser considerada a inserção da vogal enclítica $-\boldsymbol{i}$ no fim de certas formas verbais, que, porém, no caso de verbos ocorre como um fenómeno fortemente condicionado pelo contexto linguístico.

\subsection{Inserção da vogal enclítica $-i$ condicionada pela ligação do verbo com pronomes clíticos}

Trata-se de um fenómeno com maior ocorrência no centro de Portugal, perto da fronteira com Espanha, especialmente na zona subdialetal de Portalegre e Castelo Branco ${ }^{9}$, e também em Trás-os-Montes, de novo perto da fronteira luso-espanhola ${ }^{10}$, compartindo ambas as regiões a característica de se situarem no interior do país e serem raianas, linguisticamente detentoras de um caráter bastante arcaico, já que tanto a zona de Trás-os-Montes como a área de Castelo Branco e Portalegre representam regiões dialetais onde se mantêm algumas das variantes mais antigas de todo o Portugal.

É um fenómeno que não afeta somente a $1 .^{a}$ pes. do sing., que é o foco da nossa abordagem, mas também outras classes de palavras ou outras formas verbais. Aparece, tipicamente, nas palavras que acabam em - $\boldsymbol{r}$, como, por exemplo, senhori, e portanto também, logicamente, nos infinitivos, levando-nos a deparar com formas como cantari, espalhadas por todo o território de Portugal, cumprindo assim o pressuposto sobre o caráter geral de alterações fonéticas e a presença de um certo contexto fonético condicionador da sua ocorrência. Quando surge nas formas conjugadas do verbo, é geralmente derivado ao contexto linguístico, sendo o contexto mais próprio as terminações $\boldsymbol{s} \boldsymbol{s}$ ou $\boldsymbol{-} \boldsymbol{z}$ da $1 .{ }^{\mathrm{a}}$ pes. do sing. do pretérito perfeito simples do indicativo e do presente do indicativo ou da $3 .^{a}$ pes. do sing. do pretérito perfeito simples do indicativo ou presente do indicativo, que são depois combinadas com o pronome clítico da 3. ${ }^{\mathrm{a}}$ pes. do sing. ou do pl. do acusativo (ou seja, $\boldsymbol{o}, \boldsymbol{a}, \boldsymbol{o s}, \boldsymbol{a s}$ ). Nestes casos não acontece a apócope da consoante final $\boldsymbol{- s}$ ou $\boldsymbol{-} \boldsymbol{z}$ nem a complementação do pronome clítico com a consoante $\boldsymbol{- l}$, tal como dita a norma, acrescentando-se, em vez disso, a vogal - $\boldsymbol{i}$, que deste modo impede a apócope. Surgem, então, as seguintes formas:

$$
\text { ex. } 1 \text { eu FIZ + O = FIZI-O ['fiziu] (em vez de FI-LO ['filu]) }
$$

\footnotetext{
9 Segundo os dados tirados das teses dialetais escritas nos anos 50 e 60 do século XX por exemplo na localidade de Nisa. (Svobodová 2011: 118).

10 Segundo resultados obtidos dos inquéritos feitos por Lindley Cintra e realizados entre os anos 70 e 90 do século XX. (Svobodová 2011: 119).
} 
Quanto à origem deste fenómeno, somos confrontados com várias teorias sobre como terá surgido, entre as quais prevalece aquela que o explica como a forma antiquada do verbo. Leite de Vasconcelos fala sobre um exemplo de manutenção da forma verbal arcaica que era típica do antigo português, do galego e do leonês. Supõe que, sob a influência do pronome clítico, terá então ocorrido a apócope de vogal final que existia no latim (quando a $1 .{ }^{\text {a }}$ pes. do sing. do pretérito perfeito simples do indicativo terminava em - $\boldsymbol{i}$ longo e a $3 .^{\mathrm{a}}$ pes. do sing. do pretérito perfeito simples do indicativo em - $\boldsymbol{i}$ breve), pelo que o pronome acaba por aderir à forma "latinizada" do verbo (Vasconcelos 1929: 36-37). Exemplifiquemos o que ocorre no caso do verbo FAZER:

ex. 2

$$
\begin{aligned}
& \text { 1. }{ }^{a} \text { pes. do sing. - fềcī : fềcī }+o>\text { ficī }+o>\text { fizi-o } \\
& \text { 3. }{ }^{\text {a }} \text { pes. do sing. }- \text { fēcit }>\text { fēč }: \text { fēc } \breve{~}+o>\text { fēce }+o>\text { feze-o }
\end{aligned}
$$

Podemos ver que na $1 .{ }^{\mathrm{a}}$ pes. do sing. o pronome adere à forma verbal FECI e que esta forma passa depois por um processo de metafonia, quando, sob influência da vogal na sílaba final, o - $\boldsymbol{e}$ no radical fecha para $\boldsymbol{i} \boldsymbol{i}$, surgindo assim formas FICI-O e depois FIZI-O. O mesmo processo ocorre na 3. ${ }^{a}$ pes. do sing.; só que neste caso não há processo de metafonia no radical, mantendo-se lá a vogal, mas havendo alteração na desinência, dado que o - $\boldsymbol{i}$ breve fecha para - $\boldsymbol{e}$ semifechado, o que faz surgir formas como FEZE-O ${ }^{11}$.

No entanto, a pesquisa baseada no corpus dialetológico de Cintra mostra que a justificação da existência deste fenómeno com base na sua evolução histórica não é inteiramente satisfatória para explicar todos os casos da sua ocorrência. Pelo contrário, encontramos no corpus várias maneiras possíveis de provar que se trata só de uma mera alteração fonética, suscetível de ocorrer independentemente da evolução prévia.

Primeiro, um fenómeno semelhante ocorre também na $1 .^{a}$ pes. do pl. do pretérito perfeito simples do indicativo ou do presente do indicativo, cuja terminação típica é também -s. É assim que deparamos com casos como:

$$
\begin{aligned}
& \text { ex. } \left.3 \text { PUSEMOS + AS = PUSEMESI-AS [pu'zeməzir } \int\right] \\
& \text { (em vez de PUSEMO-LAS[pu'zemule } \left.\int\right] \text { ) } \\
& \text { VENDEMOS + O = VENDEMOSI-O [vẽ'demuziu] } \\
& (\text { em vez de VENDEMO-LO [vẽ'demulu] })^{12}
\end{aligned}
$$

Ora aqui não existe nenhuma justificação etimológica, uma vez que o - $\boldsymbol{i}$ final não existia nestas formas verbais, nem no latim. Assim, seria pouco consistente explicar o fenómeno nas formas verbais da $1 .^{\mathrm{a}}$ pes. do sing. e da 3. ${ }^{\mathrm{a}}$ pes. do sing. como manutenção das formas arcaicas e na forma da $1 .^{a}$ pes. do pl. como inserção do -i enclítico por motivos fonéticos.

Em segundo lugar, o fenómeno é claramente condicionado pelo contexto fonológico em que sempre ocorre. $\mathrm{O}$-i enclítico aparece não só quando o pronome clítico segue a forma verbal que acaba em $\boldsymbol{s}$ ou $\boldsymbol{-} \boldsymbol{z}$, mas também entre a terminação $\boldsymbol{- \boldsymbol { s }}$ do plural do substantivo e o clítico na posição proclítica, como se nota no seguinte exemplo ${ }^{13}$ :

11 Veja-se, por exemplo, Piel (1944: 15) ou Hricsina (2015: 142-143).

12 Exemplos tirados da aldeia de Faia, no nordeste de Portugal, a sul do rio Douro (Svobodová 2011: 118).

13 Exemplo tirado da vila de Nisa, na zona de Portalegre (Svobodová 2011: 118). 


\section{ex. 4 As moscas o comem ['mofkrziu'komãj]}

Podemos, por conseguinte, deduzir que não é a terminação verbal que desempenha o papel decisivo, mas antes o arquifonema /S/ como tal, seja qual for a classe de palavras do item lexical ao qual apareça acrescentado.

Finalmente, é preciso excluir também a possibilidade de se tratar de um fenómeno de caráter morfológico, ou seja, com papel distintivo ao nível morfológico de paradigmas flexionais. $\mathrm{O}$ facto de o dito fenómeno aparecer predominantemente nas $1 .{ }^{\mathrm{a}} \mathrm{e} 3 .^{\mathrm{a}}$ pes. do sing. do pretérito perfeito simples do indicativo dos verbos irregulares apoiaria, eventualmente, esta hipótese; como as duas pessoas verbais diferem em maior ou menor grau de abertura da vogal no radical (como vemos, por ex., no caso de FIZ - FEZ), seria lógico aplicar a inserção da vogal -i enclítica apenas numa delas para a diferenciar da outra de maneira mais percetível. Porém, a ocorrência deste fenómeno prova que tal não é o caso. Quando ele aparece numa dada região, surge sempre simultaneamente na $1 .^{\text {a }}$ pes. do sing. e na $3 .^{\text {a }}$ pes. do sing., o que significa que não desempenha nenhum papel distintivo a nível morfológico entre estas duas pessoas formalmente próximas.

Baseando-nos nos factos acima expostos, podemos então concluir que se trata de um fenómeno puramente fonético, sem uma motivação etimológica mais profunda e que, no caso dos verbos, provavelmente mais não representa do que apenas uma tentativa de evitar formas desagradáveis e complicadas passíveis de ocorrer quando anexamos o pronome clítico ao verbo e cujo uso, segundo este modelo, se vem posteriormente a alargar também a outros contextos foneticamente semelhantes.

\section{Alterações morfológicas}

Por alterações de caráter morfológico entendemos as alterações da flexão verbal que, de maneira significativa, atingem todo o paradigma flexional. Não são resultado acidental de um fenómeno fonético geral, sendo, pelo contrário, aplicadas propositadamente a uma dada forma verbal por duas razões completamente opostas: ou para assemelhar a forma verbal a uma outra forma já existente, ocorrendo, assim, um processo de analogia, ou para a diferenciar de uma outra forma verbal já existente, evitando a sua fusão e criando desta forma uma dissimilação. Contrariamente às alterações fonéticas, no caso da flexão da $1 .^{a}$ pes. do sing. do pretérito perfeito simples do indicativo a ocorrência dos dois processos de caráter morfológico está longe de ser escassa.

\subsection{Alterações motivadas por analogia}

O processo de assimilação analógica significa que a desinência verbal se assimila à outra desinência já existente na língua, que é, regra geral, tida como mais regular ou mais frequente. Assim, o objetivo deste processo é uma certa uniformização de um paradigma flexional, tido pelos falantes como demasiado irregular. 


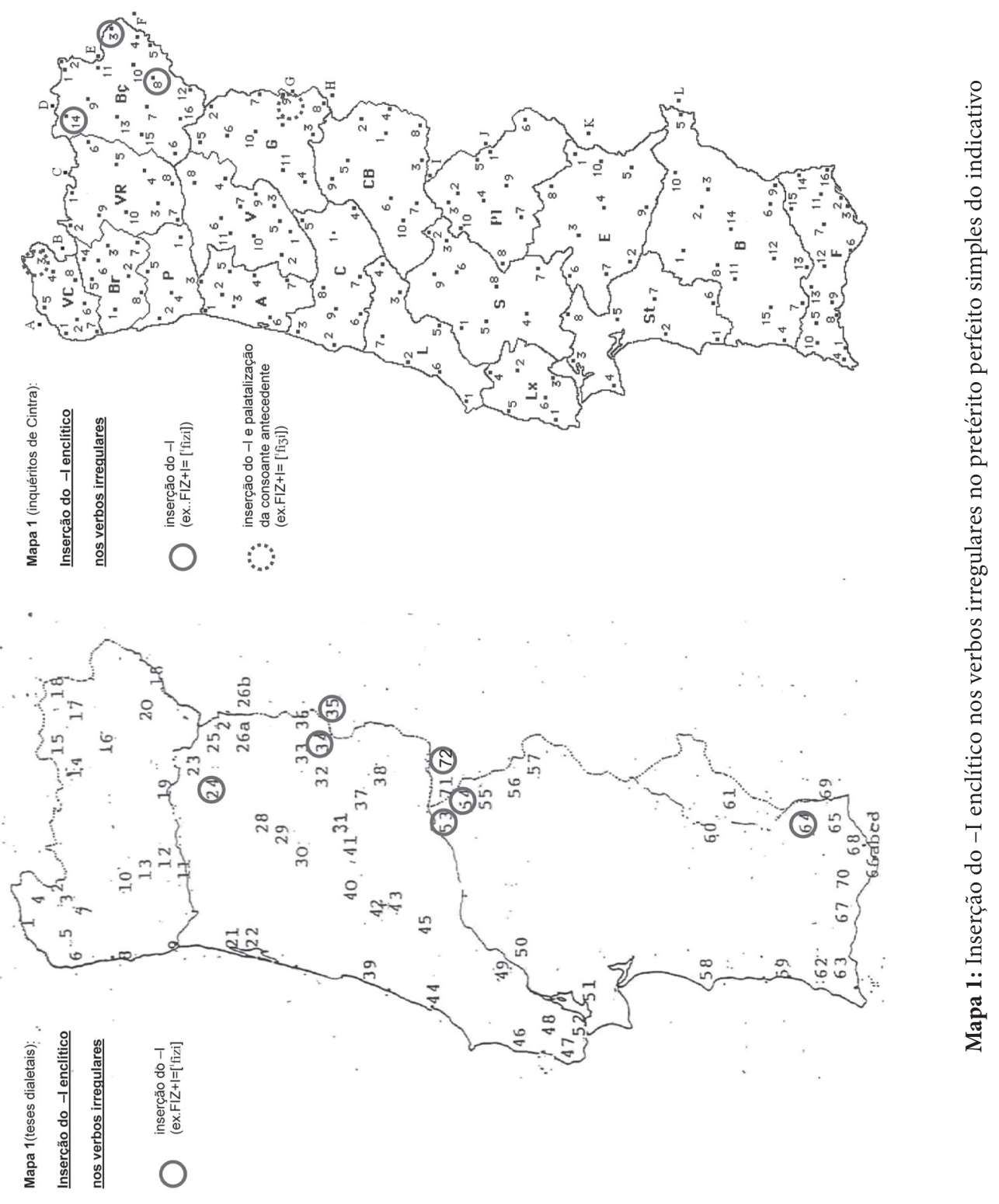


Este processo é, obviamente, bastante frequente e visto como um dos mais naturais na língua. É, antes do mais, típico dos verbos quase regulares, que registam apenas uma alteração ligeira de uma vogal ou consoante no radical da $1 .^{a}$ pes. do sing. do presente do indicativo (como, por ex., PERDER), ou dos verbos com alteração vocálica mais complexa, que atinge não apenas a $1 .^{a}$ pes. do sing. do presente do indicativo (como, por ex., FRIGIR) ${ }^{14}$. Serve para minimizar ou apagar por completo estas pequenas irregularidades, seja através da adaptação da pessoa que é irregular às pessoas regulares, seja através da adaptação das pessoas regulares à pessoa irregular. Assim, apercebemo-nos de formas como:

\section{ex. 5 PERDER $>$ eu PERDO, tu PERDES (em vez de PERCO, PERDES) COBRIR > eu CUBRO, tu CUBRES, ele CUBRE (em vez de CUBRO, COBRES, COBRE) FUGIR > eu FUJO, tu FUJES, ele FUJE (em vez de FUJO, FOJES, FOJE) ${ }^{15}$}

Além disso, o processo pode até ser aplicado no caso de verbos completamente regulares, assimilando a sua conjugação à conjugação de algum verbo irregular, cujo aparecimento na língua seja percebido como mais frequente. Um caso prototípico é o do verbo ANDAR, cuja conjugação no pretérito perfeito simples do indicativo se assemelha à conjugação do verbo TER, o que faz com que tenhamos formas como eu ANDIVE, tu ANDIVESTE, ele ANDEVE ${ }^{16}$.

Em relação aos verbos fortes, isto é, verbos que divergem do seu paradigma flexional de maneira radical, mantendo no pretérito perfeito simples do indicativo o acento na vogal temática apenas na 2. ${ }^{\mathrm{a}}$ pes. do sing. e nas $1 .^{\mathrm{a}}, 2 .^{\mathrm{a}}$ e $3 .^{\mathrm{a}}$ pes. do $\mathrm{pl} .^{17}$, o processo de analogia é muito mais esporádico. Aparece, em geral, precisamente no pretérito perfeito simples do indicativo e atinge, antes do mais, estas duas pessoas com o acento deslocado para o radical, ou seja, a $1 .{ }^{\mathrm{a}}$ pes. do sing. e a $3 .^{a}$ pes. do sing., tentando regularizar a realização da vogal no radical.

\subsubsection{Uniformização do paradigma flexional da $1 .{ }^{a}$ pes. do sing. e $3 .^{a}$ pes. do sing.}

Os verbos com alteração da posição do acento na $1 .^{\mathrm{a}}$ pes. do sing. e na $3 .^{\mathrm{a}}$ pes. do sing. do pretérito perfeito simples do indicativo sofrem também a alteração da vogal no radical das respetivas pessoas, diferenciando-se estas duas pessoas por diferente grau de abertura daquela vogal (ou seja, a $1 .{ }^{\text {a }}$ realiza-se com a vogal mais fechada, enquanto a $3 .^{\text {a }}$ se realiza com a vogal mais aberta, o que é ilustrado, por exemplo, pelo verbo FAZER > eu FIZ, ele FEZ). Estes verbos

14 Estes verbos são geralmente considerados irregulares, admitindo-se, no entanto, que a sua irregularidade consiste apenas na diferença de timbre vocálico do radical, o que se reflete também na grafia, enquando no caso de verbos como, por ex., MOVER ou DEVER, que são considerados regulares, existe a mesma irregularidade fonética. Assim, a única diferença entre os dois tipos de verbos consiste no facto de, no caso do segundo grupo de verbos, a irregularidade não se notar na forma escrita. Devido a isso, os verbos do primeiro grupo costumam ser também designados como verbos com alternância vocálica. Veja-se, por exemplo, Cunha (1999: 412).

15 Exemplo tirado da aldeia de Baleizão e dos concelhos de Elvas e Alandroal, no Alentejo (Svobodová 2011: 115).

16 Esta conjugação encontra-se espalhada por todo o Portugal, especialmente nas províncias do Alentejo, das Beiras e Trás-os-Montes (Vasconcelos 1987: 115).

17 Enquanto as $1 .^{\mathrm{a}}$ e $3 .^{\mathrm{a}}$ pes. do sing. sofrem a deslocação do acento para o radical, o que causa muita irregularidade no paradigma flexional (por ex. verbos como TRAZER ou FAZER). 
tendem depois, nas variantes diatópicas, a aceitar analogicamente o paradigma de verbos que tenham a mesma vogal no radical da $1 .^{a}$ pes. do sing. e da $3 .^{a}$ pes. do sing. do pretérito perfeito simples do indicativo ${ }^{18}$ para se uniformizarem as vogais do radical, confundindo-se, assim, estas duas subcategorias de irregularidades.

Há três variantes diferentes desta adaptação. Na primeira variante a $1 .^{\mathrm{a}}$ pes. do sing. passa a ter a forma da $3 .^{a}$ pes. do sing., enquanto a $3 .^{a}$ pes. do sing. não muda de forma, acabando por se fundir (veja-se ex. 6a). Na segunda variante acontece o contrário, ou seja, a 3. ${ }^{a}$ pes. do sing. passa a ter a forma da $1 .^{a}$ pes. do sing., enquanto a $1 .{ }^{a}$ pes. do sing. não muda de forma, o que faz com que, no fundo, se fundam (veja-se ex. 6b). A terceira variante significa que a $1 .^{\mathrm{a}}$ pes. do sing. e a 3. ${ }^{\text {a }}$ pes. do sing. trocam as suas formas, pelo que, de facto, se mantém simultaneamente a diferença entre estas duas pessoas do verbo, ressalvando-se que, em relação à norma padrão, as vogais nos radicais das respetivas pessoas não correspondem ao que a mesma dita (veja-se ex. 6c).

$\begin{array}{ll}\text { ex. } 6 \mathrm{a} & \text { FAZER: eu FIZ > eu FEZ - ele FEZ } \\ \text { ex. } 6 \mathrm{~b} & \text { FAZER: eu FIZ - ele FEZ > ele FIZ } \\ \text { ex. } 6 c & \text { FAZER: eu FIZ > eu FEZ - ele FEZ > ele FIZ }{ }^{19}\end{array}$

É de destacar que, enquanto exemplo de analogia, esta alteração funciona só quando a troca não é mútua, ou seja, tal como funciona nos exemplos 6 a e $6 \mathrm{~b}$, quando a $1 .^{a}$ pes. do sing. passa à 3. a pes. do sing. ou vice-versa. No caso de troca mútua de vogais, o paradigma flexional, na verdade, não muda: os verbos continuam a pertencer ao grupo de verbos irregulares com diferente timbre vocálico no radical da $1 .^{\mathrm{a}}$ e 3 . $^{\mathrm{a}}$ pes. do sing. e só passaram pela troca de grau de abertura da vogal entre estas duas pessoas, pelo que esta mudança não representa mais do que uma simples alteração a nível fonético.

No entanto, há que convir que a troca mútua é até bastante rara. É muito mais frequente depararmos com formas como eu FEZ - ele FEZ ou eu FIZ - ele FIZ, sendo a primeira delas a mais comum e típica sobretudo da região do Minho. É, aliás, uma das variedades diatópicas mais arcaicas, mencionada já no século XVIII por Jerónimo Contador de Argote, na sua obra Regras da Lingua Portugueza, espelho da Lingua Latina ${ }^{20}$, como típica dos verbos irregulares (fortes), sendo tão frequente que começa a aplicar-se até nos verbos regulares. Não é, por isso, de estranhar que venhamos depois a estar perante exemplos como eu PARTIU - ele PARTIU (Svobodová 2011: 100).

Há linguistas, como Vasconcelos (Vasconcelos 1987: 115), que sustentam que na zona de Minho há, antes de tudo, troca mútua da $1 .^{a}$ pes. do sing. e da $3 .^{a}$ pes. do sing., enquanto nas Beiras ocorre só a troca da $1 .{ }^{\mathrm{a}}$ pes. do sing. pela 3. ${ }^{\mathrm{a}}$ pes. do sing. ou da $3 .^{\mathrm{a}}$ pes. do sing. pela $1 .^{\mathrm{a}}$ pes. do sing., ou seja, pressupõem que o tipo de alteração que se aplica resulta do fator geográfico e difere de zona para zona. Porém, os resultados da pesquisa no corpus não confirmaram este pressuposto de delimitação puramente geográfica. Descobrimos que numa dada região

18 Verbos como, por ex., TRAZER (eu TROUXE - ele TROUXE).

19 Exemplos tirados de Vasconcelos (1987: 115).

20 Veja-se Argote (1725; apud Neto 1970: 561-564). 
nem sempre existe uma só variante da troca e que a variante de alteração que se aplica é em diferentes dialetos bastas vezes mais condicionada pelo tipo de verbo do que pela região em que é detetada, o que comprova que o fator da distribuição geográfica não é decisivo na aplicação desta alteração. Para especificar, há zonas (geralmente nas províncias do Minho e de Trás-osMontes) em que a alteração ocorre somente nos verbos SER ou IR, tratando-se sempre de troca mútua de formas das 1. a e 3. ${ }^{\mathrm{a}}$ pes. do sing. (Vasconcelos 1987: 116; Svobodová 2011: 111); noutras áreas, como na costa minhota, acontece só com verbos que têm alteração das vogais - $\boldsymbol{e}$ e - $\boldsymbol{i}$ no radical (como, por ex., FAZER: eu FIZ - ele FEZ; veja-se ex. 7a) e noutras ainda, como em Trás-os-Montes, Castelo Branco e Portalegre, pode ocorrer, pelo contrário, só nos verbos que alteram a vogal - $\boldsymbol{u}$ e -o do radical (como, por ex., PODER: eu PUDE - ele PÔDE; veja-se ex. 7b), atingindo predominantemente os verbos PODER e PÔR ${ }^{21}$.

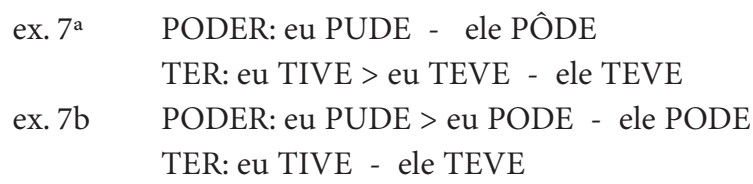

Nestes exemplos podemos, então, identificar tentativas de privar o paradigma verbal da única forma verbal com vogal alternativa no radical, unificando-se, assim, as vogais do radical em todas as pessoas do singular. No entanto, é de salientar que esta alternância dispõe de pouca sistematicidade.

\subsection{Alterações motivadas por dissimilação}

Passando agora para as alterações motivadas por dissimilação, há que deixar claro que o seu objetivo é, obviamente, contrário ao das alterações assimiladoras; por outras palavras, trata-se de um tipo de alteração em que tentamos diferenciar as formas verbais demasiado semelhantes ou até idênticas para as tornar mais facilmente identificáveis e mais visivelmente marcadas como próprias de uma só pessoa verbal.

Este fenómeno é característico apenas dos verbos irregulares, especialmente daqueles com formas idênticas na $1 .^{\mathrm{a}}$ pes. do sing. e na $3 .^{\mathrm{a}}$ pes. do sing. do pretérito perfeito simples do indicativo, como, por exemplo, o verbo TRAZER. Deparamos com vários modos de diferenciação destas formas idênticas, quando se tira partido seja de recursos fonéticos, alterando-se o timbre vocálico do radical das pessoas idênticas, seja de recursos morfológicos e etimológicos, acrescentando-se desinências verbais de pessoa e número aos verbos formalmente uniformes ou substituindo uma das pessoas facilmente confundíveis pela forma arcaica do verbo.

Debrucemo-nos agora sobre exemplos concretos destas duas soluções possíveis.

21 Os exemplos abaixo expostos são tirados do corpus das teses e dos inquéritos de Cintra, sendo a variante do exemplo 7a própria da região do Minho, enquanto a variante no 7b o é de Trás-os-Montes (Svobodová 2011: 132). 


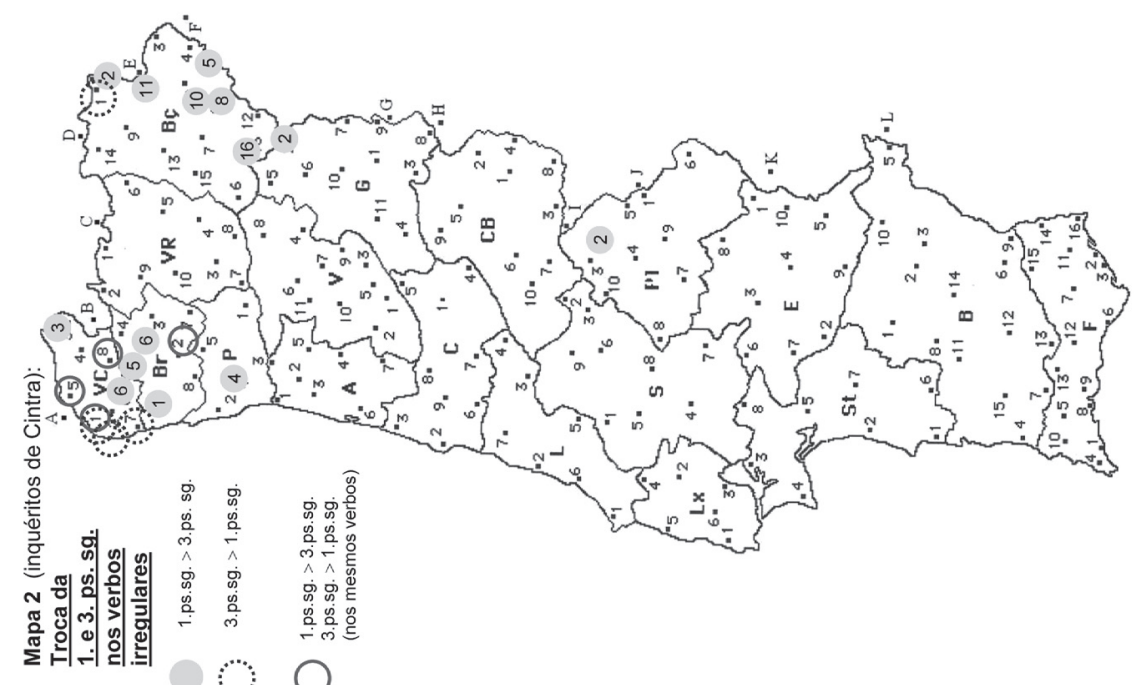

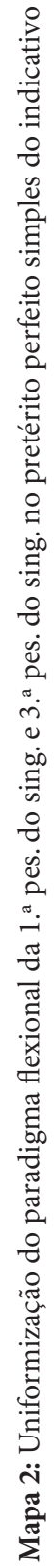




\subsubsection{Uso de formas verbais arcaicas}

A substituição de uma das formas verbais uniformes por uma forma arcaica do verbo representa uma solução relativamente rara e restrita ao tipo de verbo, mas, mesmo assim, interessante, na medida em que mostra claramente que esta alteração ocorre, regra geral, propositadamente para diferenciar as duas pessoas problemáticas, ou seja, as $1 .^{\mathrm{a}}$ e $3 .^{\mathrm{a}}$ pes. do sing. Acontece, primeiro do que tudo, no caso do verbo TRAZER, quando a sua forma da $1 .{ }^{\text {a }}$ pes. do sing. do pretérito perfeito simples do indicativo é substituída pela forma mais arcaica, enquanto na $3 .^{\mathrm{a}}$ pes. do sing. do mesmo tempo se conserva a forma normativa, tal como se vê no exemplo a seguir, proveniente do Algarve, concretamente da zona de Faro (Svobodová 2011: 122):

\section{ex. 8 TRAZER: eu TROUXE > eu TROUVE - ele TROUXE}

Em princípio, não é surpreendente que esta alteração ocorra especialmente no caso deste verbo. A conjugação do verbo TRAZER surgiu da fusão de conjugações de dois verbos diferentes: do verbo TRAHERE, em concreto da sua $1 .{ }^{\text {a }}$ pes. do sing. do pretérito perfeito simples do indicativo TRAXI, que depois ditongou para TREIXE, velarizando-se mais tarde o ditongo para TROIXE/TRUISE ou TROUXE, sendo estas duas variantes equivalentes, e do verbo TRAGERE, em concreto da sua $1 .^{a}$ pes. do sing. do pretérito perfeito simples do indicativo TRACUI, que sonorizou para TROUGUE e depois mudou para TROUVE, fazendo analogia com a forma verbal HOUVE, considerada mais frequente ${ }^{22}$. Já no século XVII a forma TROUXE começa a predominar, enquanto TROUVE é considerada forma rural, usada pelos menos letrados. ${ }^{23}$ As variantes dialetais da conjugação deste verbo refletem perfeitamente a sua complicada evolução etimológica, o que nota já Vasconcelos ao mencionar que nos dialetos portugueses existem quatro realizações possíveis da $1 .^{\text {a }}$ pes. do sing. do verbo TRAZER: TROUFE, TROUVE e TROIXE, típicas da região interamnense, e TRUIXE, típica das Beiras (Vasconcelos 1987 :117). Segundo as suas observações, as variantes mais arcaicas aparecem, pois, nas regiões consideradas mais conservadoras, ou seja, nas Beiras e no Norte em geral, o que, porém, os inquéritos de Cintra e as teses dialetais nem sempre confirmam. Enquanto a variante com ditongo oi (TROISE/TRUISE), que representa a variante antiquada do ditongo antigo ou, ocorre essencialmente nas Beiras, a variante TROUVE, considerada ainda mais arcaica, é sobretudo detetada no sul de Portugal, especialmente na província do Algarve. Assim, baseando-nos no corpus, podemos chegar à conclusão de que as variantes arcaicas do verbo TRAZER não são distribuídas apenas nas zonas consideradas arcaizantes e que, portanto, provavelmente, não se trata de mera confusão entre múltiplas formas surgidas devido à diferente origem etimológica.

Muito pelo contrário, voltando ao aspeto linguístico, podemos ver que, através da diferenciação etimológica da forma da $1 .{ }^{a}$ pes. do sing., é perfeitamente possível dissimilar as duas pessoas uniformes e que o uso de formas arcaicas, qualquer que seja a alternativa escolhida, não é acidental, mas intencional. É preciso mencionar também que a troca por variantes arcaicas pode aparecer não só na $1 .^{a}$ pes. do sing. como também em todas as restantes pessoas, e que

23 Tal como afirma, por ex., João Franco Barreto na sua Ortografia da Lingua portuguesa (Barreto 1671: 54). 
este é um caso bastante frequente. É, contudo, de salientar que, apesar de as variantes arcaicas ocorrerem em todo o paradigma verbal, geralmente se mantém uma certa diferenciação de formas verbais das $1 .^{\mathrm{a}}$ e $3 .^{\mathrm{a}}$ pes. sing., só que desta vez realizando-se através de diferente grau de abertura do timbre vocálico no radical, ou seja, utilizando recursos em princípio fonéticos, como vemos no exemplo 9:

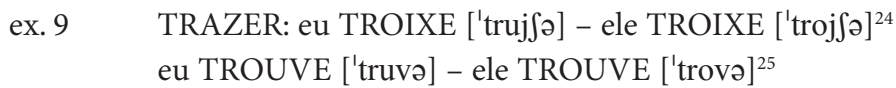

Esta alteração da abertura vocálica demonstra assim, mais uma vez, que, mesmo quando as formas arcaicas como tais não servem para diferenciar as duas pessoas, o seu uso nas duas pessoas verbais problemáticas é propositadamente diferenciado, o que comprova a tendência geral para dissimilação de formas verbais idênticas.

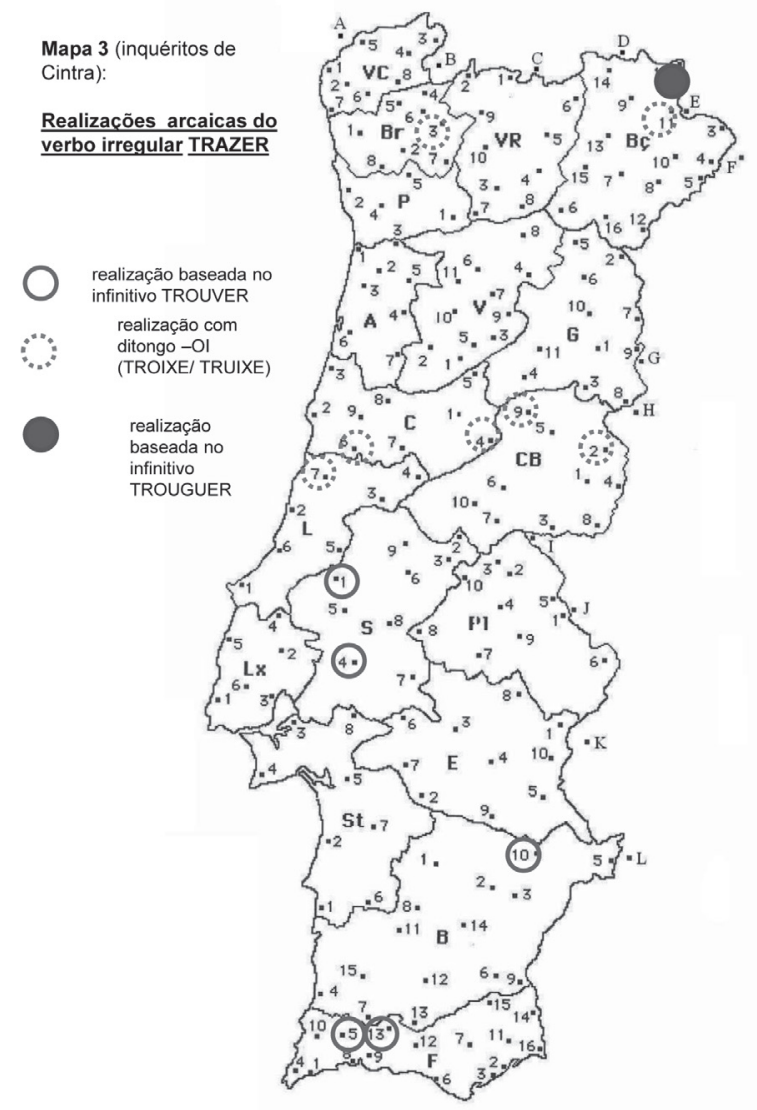

Mapa 3: Realizações arcaicas do verbo irregular TRAZER 
3.2.2. Diferenciação da $1 .{ }^{a}$ pes. do sing. e $3 .{ }^{a}$ pes. do sing. do pretérito perfeito simples idênticas através da alteração do timbre vocálico no radical

Esta conclusão leva-nos a outro fenómeno motivado, muito provavelmente, pela tendência de diferenciar formas verbais idênticas, em concreto ao fenómeno de alteração do timbre vocálico no radical dos verbos cujas $1 .{ }^{\mathrm{a}} \mathrm{e} 3 .^{\mathrm{a}}$ pes. do sing. são idênticas na língua padrão. Por outras palavras, no caso dos verbos como, por exemplo, TRAZER, a 1. a pes. do sing. do pretérito perfeito simples realiza-se com o timbre vocálico fechado (TROUXE $>\left[\right.$ 'trusa]), enquanto a $3 .^{a}$ pes. do sing. do mesmo tempo se caracteriza por um timbre vocálico mais aberto (TROUXE $>$ ['trosa]), assim se imitando o paradigma flexional de verbos como, por exemplo, FAZER, em que a alteração do timbre vocálico nas duas pessoas representa realização normativa.

Como acabamos de ver, este fenómeno ocorre muitas vezes em estreita ligação com outras alterações ocorrentes nos verbos (por exemplo, com a aplicação de formas verbais arcaicas), como mostrámos no caso do verbo TRAZER. Todavia, é de notar que deparamos com ele não apenas no caso deste verbo e não apenas em combinação com formas arcaicas, tal como vimos no exemplo 9: está-se perante um fenómeno muito mais amplo, que atinge também as realizações em princípio normativas deste próprio verbo (como observamos no exemplo 10a) e também de outros verbos irregulares, especialmente do verbo SABER (tal como vemos no exemplo 10b).

\section{ex. 10a TRAZER: eu TROUXE ['trusə] - ele TROUXE ['trosə] $]^{26}$ \\ ex. 10b SABER: eu SOUBE ['subə] - ele SOUBE['sobə] ${ }^{27}$}

É um fenómeno só escassamente mencionado nos textos dialetológicos ${ }^{28}$, o que se deve ao facto de ser, hoje em dia, considerado um traço típico da linguagem coloquial, isto é, um traço marcado mais socialmente do que diatopicamente. No entanto, do ponto de vista da sua distribuição diatópica, podemos constatar que, apesar de descrito como fenómeno frequente em todo o território de Portugal continental, segundo o corpus é particularmente frequente na zona de dialetos centro-meridionais, nas províncias da Beira Baixa, Estremadura, Alentejo e Algarve, enquanto no Norte, segundo os inquéritos de Cintra, encontramos predominantemente as realizações normativas. Leve-se, contudo, em consideração que os inquéritos elaborados por Cintra se realizaram nos anos 1970 - 2000 e que nos últimos vinte anos o fenómeno pode terse tornado muito mais popular e menos delimitado geograficamente, o que, de facto, confirma a própria Elisabete Soalheiro, cuja tese de doutoramento, em que aborda a ocorrência frequente da alteração do timbre vocálico dos verbos como TRAZER, se dedica apenas aos dialetos do

26 Realizações encontradas por todo Portugal, especialmente no Algarve, Alentejo, Estremadura e também na zona fronteiriça (Svobodová 2011: 126).

27 Realização própria da zona de dialetos centro-meridionais, em geral. Na zona fronteiriça podemos encontrar também outras realizações possíveis do verbo SABER, algumas das quais bastante específicas, tal como, por exemplo, a de Nave de Haver e Alamedilla, quando a $1 .^{\mathrm{a}}$ pes. do sing. se realiza como ['subə], enquanto a $3 .^{\mathrm{a}}$ ps.sing. se realiza como [se'bew], ou seja, a 3.ps.sing. comporta-se como se fosse conjugada da forma regular (Svobodová 2011: 127).

28 Uma das exceções é Soalheiro, que, na sua tese de doutoramento, fala sobre a ocorrência frequente de formas como «eu ['trusə]»e «ele ['trosə]» (Soalheiro 2002: 187-188). 


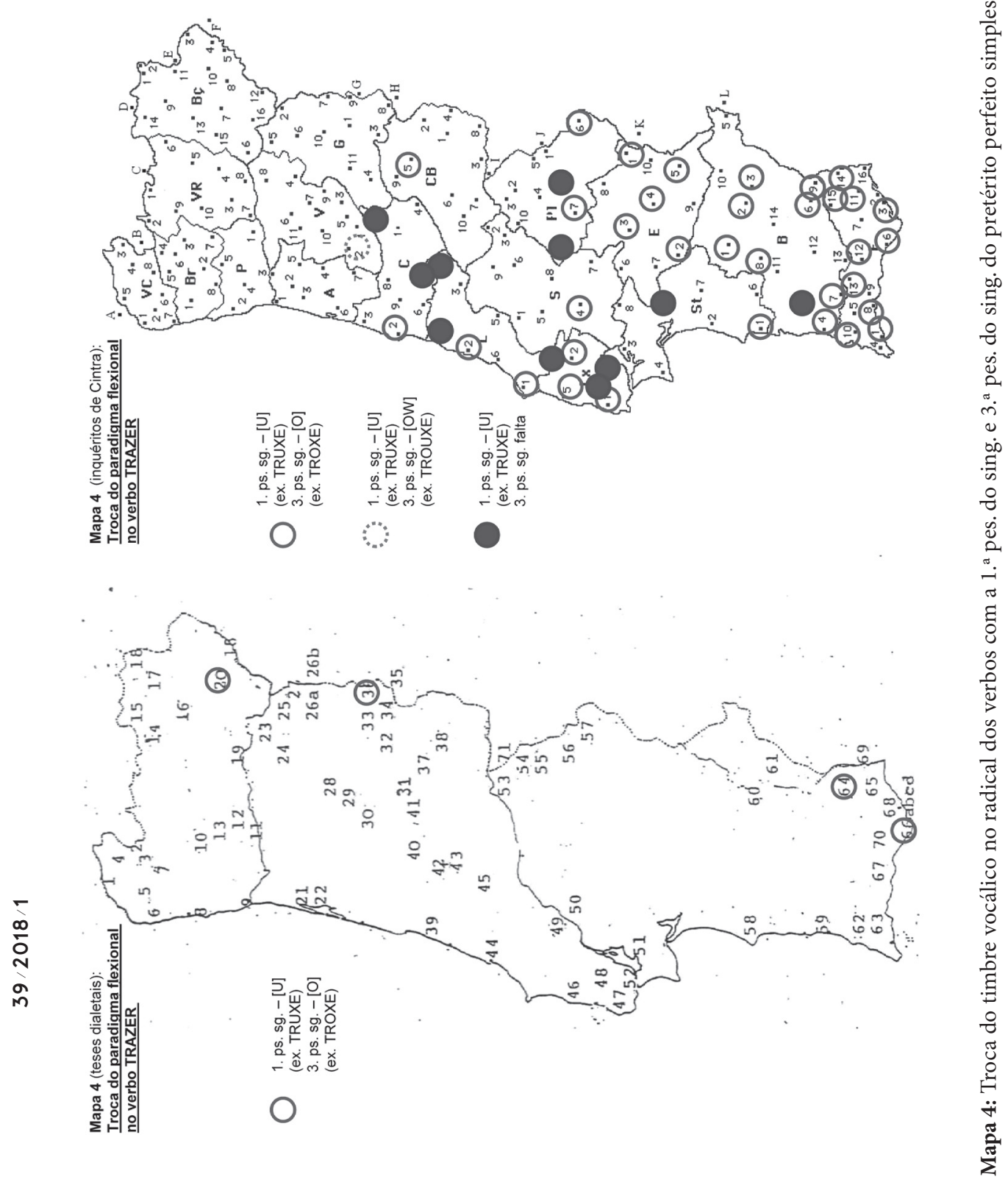


norte de Portugal (veja-se a nota 28). De qualquer maneira, mesmo que hoje em dia constitua um fenómeno mais social do que diatópico, a sua ocorrência frequente no corpus é inegável e, juntamente com a sua penetração rápida na língua coloquial, comprova a hipótese de que a tendência dos falantes para distinguir duas formas verbais idênticas a fim de evitar a sua confusão é bastante forte e que, para atingir este objetivo, o recurso a meios fonéticos dissimiladores representa a solução mais natural.

\section{Alterações morfonológicas}

Finalmente, por alterações morfonológicas entendemos as alterações fonéticas da desinência ou do radical do verbo que, num segundo plano, sejam passíveis de adquirir papel distintivo a nível morfológico e levar a uma melhor diferenciação de pessoas verbais facilmente confundíveis ou até idênticas. Daí estas alterações ocorrerem principalmente nos verbos irregulares com $1 .^{\text {a }}$ pes. do sing. e $3 .^{a}$ pes. do sing. do pretérito perfeito simples idênticas ou nos verbos cujas $1 .^{\text {a }}$ pes. do sing. e $3 .^{\text {a }}$ pes. do sing. do pretérito perfeito simples do indicativo difiram só no grau de abertura da vogal no radical, sendo os dois casos considerados os mais problemáticos dentro de todos os paradigmas conjugacionais.

Tal como no caso de alterações morfológicas, existem várias maneiras de atingir este objetivo dissimilador, entre as quais é considerada mais prototípica a da nasalização da vogal no radical ou na desinência.

\subsection{Nasalização da vogal no radical ou nas desinências da $1 .{ }^{\mathrm{a}}$ pes. do sing. ou $3 .{ }^{\mathrm{a}}$ pes. do sing. do pretérito perfeito simples do indicativo}

Trata-se de uma das mais antigas alterações a nível diatópico com a qual deparamos - principalmente, mas não só - em ambos os subgrupos de verbos irregulares já mencionados, isto é, tanto nos verbos com a $1 .^{\text {a }}$ pes. do sing. e a $3 .^{\text {a }}$ pes. do sing. do pretérito perfeito simples idênticas, como nos verbos cujas $1 .^{\mathrm{a}}$ pes. do sing. e 3. ${ }^{\mathrm{a}}$ pes. do sing. diferem pelo timbre vocálico. Assim, nas variantes diatópicas encontramos formas, exemplificadas em 11a e 11b, em que pelos vistos se mantêm as referências normativas do verbo, mas no caso da $1 .{ }^{a}$ pes. do sing. ocorre a nasalização da vogal no radical:

\section{ex. 11a TRAZER: eu TROUXE ['trõsi] - ele TROUXE ['trosi] \\ ex. 11b FAZER: eu FIZ ['fĩf] - ele FEZ ['fe $\left.\int\right]^{29}$}

Apesar de representar um fenómeno conhecido já desde há séculos, ainda não se chegou a acordo quanto à sua origem. Vasconcelos sustém que a nasalização ocorre sob influência do verbo VIR, que é muito frequente na língua falada e cuja forma da $1 .^{a}$ pes. do sing. do pretérito perfeito simples é VIM, contendo, pois, a vogal nasal; por outro lado, não põe também de parte 
que se possa tratar de um arcaísmo baseado na analogia com a forma latina da $1 .^{\text {a }}$ pes. do sing. do presente do indicativo do verbo SER, que é SUM (Vasconcelos 1987: 110). Outros autores, como, por exemplo, Piel, atribuem esta alteração à influência do galego, cuja terminação típica da $1 .^{\text {a }}$ pes. do sing. do pretérito perfeito simples é -ín (Piel 1944: 11). Porém, baseando-nos no corpus criado a partir dos inquéritos de Cintra e das teses dialetais, descobrimos que este fenómeno não é detetável perto das fronteiras com a Galiza, sendo mais próprio da sub-região de Castelo Branco e Portalegre ${ }^{30}$, que fica fora de alcance da influência do galego. A teoria de Piel parece-nos, pois, menos viável do que a que foi apresentada por Vasconcelos.

Quanto à ocorrência deste fenómeno segundo o tipo de verbos, não podemos omitir que está tão espalhado que deparamos com ele até no caso de verbos regulares. No caso destes verbos, atinge a desinência da $1 .^{\text {a }}$ pes. do sing. do pretérito perfeito simples do indicativo dos verbos da $2 .^{\mathrm{a}}$ e $3 .^{\mathrm{a}}$ conjugação, criando, assim, formas como eu PARTI [per'tĩ]. Uma vez que sempre aparece nas zonas em que ocorre também a nasalização nos verbos irregulares, representa provavelmente uma mera ampliação do fenómeno dos verbos irregulares, dos quais é muito mais típico, para os regulares. De qualquer maneira, no caso dos verbos regulares representa apenas um tipo de alteração fonética.

No que diz respeito aos verbos irregulares, é muito mais frequente no subgrupo de verbos cujas $1 .{ }^{a}$ pes. do sing. e $3 .^{\text {a }}$ pes. do sing. diferem pelo timbre vocálico; contudo, neles desempenha também, e principalmente, só o papel da alteração fonética, acentuando nitidamente a diferença entre as duas formas, mas não servindo como recurso da sua dissimilação total.

Se, pelo contrário, a nasalização aparece no caso de verbos com a $1 .^{\mathrm{a}}$ pes. do sing. e a $3 .^{\mathrm{a}}$ pes. do sing. do pretérito perfeito simples idênticas, é muito mais marcante e revela uma função já distintiva. Pode acontecer tanto na $1 .^{\text {a }}$ pes. do sing. como na $3 .^{\text {a }}$ pes. do sing., sendo muito mais frequente na $1 .^{a}$ pes. do sing. Deve, não obstante, salientar-se que nunca ocorre nas duas pessoas ao mesmo tempo, isto é, a $1 .{ }^{a}$ pes. do sing. e a 3. a pes. do sing. sempre ficam em oposição. Assim, no caso destes verbos a nasalização é responsável pela diferenciação destas duas pessoas verbais. Comprova-se, pois, a hipótese de os próprios falantes perceberem esta alteração como um fenómeno com impacto morfológico capaz de facilitar a distinção entre duas pessoas facilmente confundíveis.

Em algumas zonas, como, por exemplo, na região de Santarém ${ }^{31}$, nota-se também que se trata de um fenómeno com pouca aleatoriedade na aplicação do processo e confirma-se a sua surpreendente sistematicidade. Olhando para os exemplos 12a e 12b, podemos ver que, nesta zona, nos verbos com alteração de grau de abertura da vogal nas $1 .{ }^{a}$ pes. do sing. e $3 .^{a}$ pes. do sing. do pretérito perfeito simples do indicativo, há nasalização apenas da $1 .^{\mathrm{a}}$ pes. do sing., enquanto no caso de verbos com a $1 .^{a}$ pes. do sing. e a $3 .^{a}$ pes. do sing. do pretérito perfeito simples idênticas é sempre e só a $3 .^{\text {a }}$ pes. do sing. a sofrer alteração:

ex. 12a TER: eu TIVE ['tĩvo] - ele TEVE ['tev]

ex. 12b SABER: eu SOUBE ['sub]- ele SOUBE ['sũb]

30 Segundo os resultados obtidos dos inquéritos de Cintra (Svobodová 2011: 149-151).

31 Nos inquéritos de Cintra (Svobodová 2011: 150). 

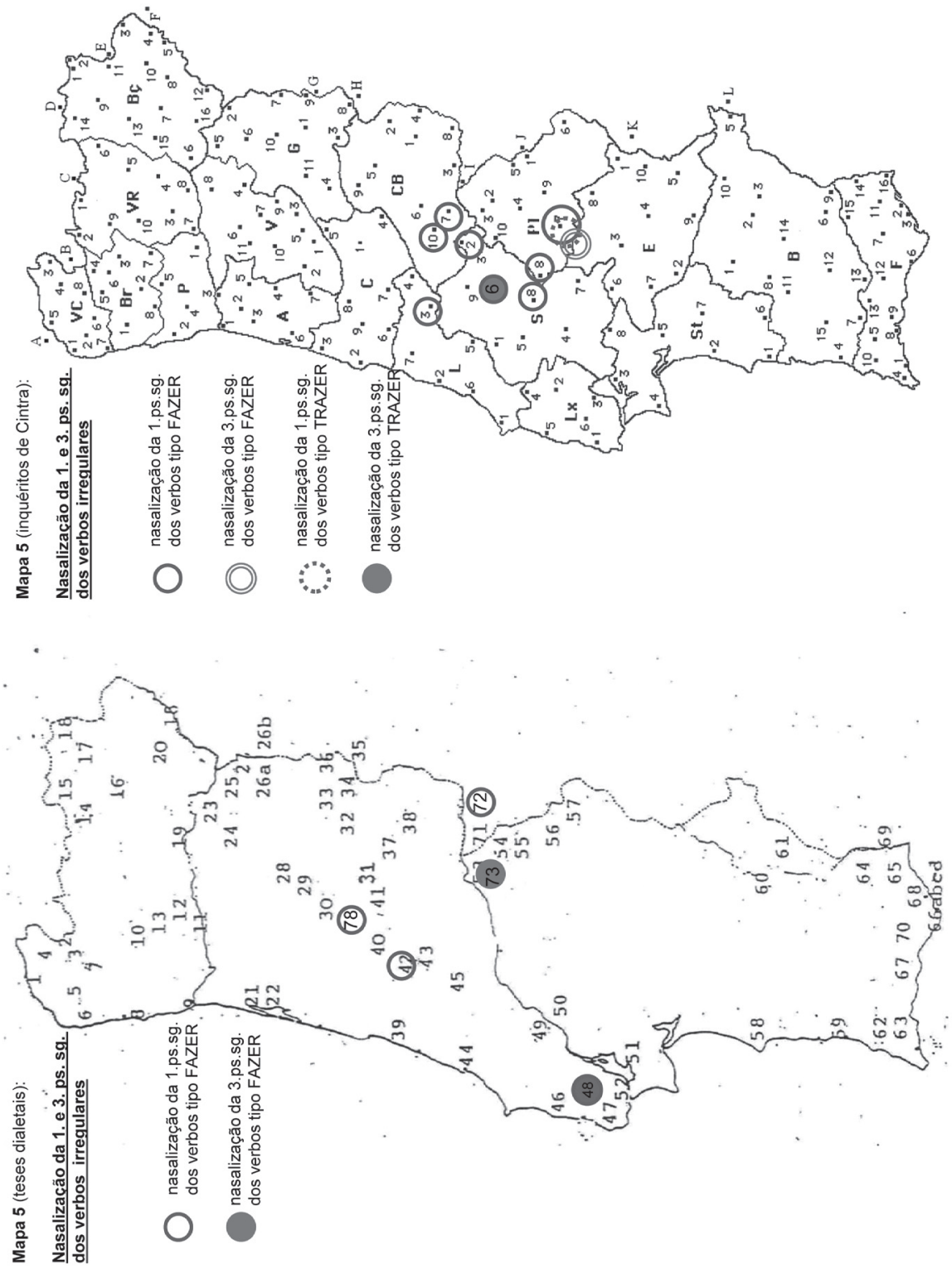
Finalmente, a importância do impacto morfológico desta alteração sentida pelos falantes nota-se também no facto de a nasalização se associar frequentemente a outras alterações cuja função é ajudar na distinção de duas formas semelhantes, pelo que esta combinação possui efeito duplo de diferenciação. Assim, como se vê no exemplo 13, podemos deparar com a combinação de nasalização e fechamento da vogal no radical nos verbos com a $10^{\text {a }}$ pes. do sing. e a 3. ${ }^{a}$ pes. do sing. idênticas. Aqui, na verdade, é o próprio fechamento que contribui para uma melhor distinção das duas pessoas; a nasalização ajuda apenas ligeiramente, enfatizando-o.

ex. 13 SABER: eu SOUBE ['sũbi]- ele SOUBE ['sobi] $]^{32}$

\section{Considerações finais}

Dos dados acima comentados podemos concluir que o verbo representa uma das classes de palavras mais dinâmicas até a nível diatópico, apesar das ideias pré-concebidas de que a variação morfológica nos dialetos portugueses é de pouca dimensão e, se existente, em geral pouco sistemática e sem uma distribuição regular e bem delimitada. Não se pode negar que há uma certa sistematicidade nas alterações flexionais dos verbos ocorrentes, como demonstra, por exemplo, o caso de nasalização cujo aparecimento ou na $1 .{ }^{a}$ pes. do sing. ou na 3 . $^{\mathrm{a}}$ pes. do sing. não é, de modo nenhum, aleatório. O mesmo se pode dizer sobre a distribuição geográfica de várias alterações, que, ao contrário de certos pressupostos, é pontualmente bem delimitada e regular, como se nota, por exemplo, e mais uma vez, no caso de nasalização, uma alteração própria da região de Castelo Branco e Portalegre, mas também no caso da troca da $1 .{ }^{a}$ pes. do sing. e da 3. ${ }^{\text {a }}$ pes. do sing., predominantemente observável na região do Minho e na fronteira de Trás-os-Montes com Espanha, o que coloca em dúvida os dois pressupostos sobre as variantes dialetais a nível morfológico.

Além disso, acabamos de ver que há até bastante heterogeneidade a nível morfológico, mesmo que seja, de vez em quando, motivada por questões fonéticas e, assim, sem grande impacto a nível morfológico, enquanto tal. Porém, como vimos, por exemplo, no caso de nasalização ou alteração do timbre vocálico no radical, até estas alterações originalmente fonéticas podem levar a maior diferenciação a nível morfológico, o que comprova a estreita ligação entre o nível fonético e o morfológico e a quase impossibilidade de os separar na análise linguística das dadas alterações. Desta interligação podemos deduzir que há suficiente justificação para a classificação de alterações ocorrentes nos verbos em três categorias básicas, proposta na introdução deste texto. Através dos fenómenos comentados pensamos ter comprovado a existência de alterações puramente fonéticas, com pouca influência no tipo de paradigma verbal, tal como a existência de fenómenos cuja influência no paradigma verbal é inegável, independentemente do facto de se tratar de uma influência intencional ou de um impacto secundário.

32 Exemplo tirado dos inquéritos de Cintra, em concreto da zona de Portalegre (Svobodová 2011: 150). 


\section{Referências bibliográficas}

Barretto, I. F. (1671). Ortografia da lingva portvgveza. Lisboa: Officina de Ioam da Costa.

Barros, M. F.; Carrilho E.; Lobo M., Saramago J.; \& Cruz, L. S. (1996). Variação linguística: perspectiva dialectológica. In I. H. Faria, E. R. Pedro, I. Duarte \& C. A. M. Gouveia (Eds.), Introdução à Linguística Geral e Portuguesa (pp. 479-502). Lisboa: Caminho.

Boléo, M. P. (1974). Unidade e variedade da língua portuguesa. Estudos de Linguística Portuguesa e Românica, 1, 253-287.

Cintra, L. F. L. (1971). Nova Proposta de Classificação dos Dialectos Galego-Portugueses. Boletim de Filologia, 22, 81-116.

- (1995). Estudos de Dialectologia Portuguesa. Lisboa: Livraria Sá da Costa.

Cuesta, P. V.; \& Luz, M. A. M. (1989). Gramática da Língua Portuguesa. Lisboa: Edições 70.

Cunha, C.; \& Cintra L. F. L. (1999). Nova Gramática do Português Contemporâneo. Lisboa: Edições João Sá da Costa.

Hriscina, J. (2015). Vývoj portugalského jazyka. Praha: Karolinum.

Neto, S. (1970). História da Língua Portuguesa. Rio de Janeiro: Livros de Portugal.

Peres, J. A.; \& Móia, T. (1997). Áreas críticas da língua portuguesa. Lisboa: Caminho.

Piel, J. M. (1944). A flexão verbal do português (estudo de morfologia histórica). <http://cvc.institutocamoes.pt/hlp/biblioteca/flexao_verbal.pdf>

Soalheiro, E. L. (2002). Flexão verbal em Português Europeu: Estudo de padrões flexionais no Português falado no Norte de Portugal com elementos de comparação com o Galego. Dissertação de Doutoramento. Universidade de Lisboa.

Svobodová, P. (2011). Verbální flexe v 1. os. j. č. minulého času prostého a její zeměpisné varianty na území kontinentálního Portugalska. Dissertação de Doutoramento. Univerzita Palackého v Olomouci <https:// theses.cz/id/j4961i?furl=\%2Fid\%2Fj4961i;so=nx;lang=en $>$.

Vasconcelos, J. L. (1987). Esquisse d'une dialectologie portugaise. Lisboa: CLUL/INIC. (1929). Dialectos alemtejanos. Revista Lusitana, IV , 13-77. 